\title{
Unveiling dolomite surface rate variability using vertical scanning interferometry
}

\author{
I. BIBI ${ }^{1,2, *}$, A. LÜTTGE ${ }^{2}$, N. K. NIAZI ${ }^{1}$
}

${ }^{1}$ University of Agriculture Faisalabad, Pakistan (*Email: irshad.niazi81@gmail.com)

${ }^{2}$ MARUM and Department of Geosciences, University of Bremen, Germany

The surface rate measurements of mineral dissolution reactions have shown variability of mineral surfaces. Although there has been considerable amount of research reporting calcite $\left(\mathrm{CaCO}_{3}\right)$ surface variability, the existence of surface heterogeneity and its effects on surface rates of dolomite $\left(\mathrm{CaMg}\left(\mathrm{CO}_{3}\right)_{2}\right)$ on interaction with aqueous solutions of variable strength, remains unexplored. This study investigated the effects of aqueous solutions of $\mathrm{NaCl}(0.05$ to $0.2 \mathrm{M})$, at acidic $\mathrm{pH}(\mathrm{pH} 3.0)$, on temporal evolution in dolomite dissolution kinetics using single pass flow-through cells. Results from a series of direct surface measurement data obtained from vertical scanning interferometry was analyzed by material flux maps and rate spectra, allowing identification and quantification of dissolution rate contributors. To the best of our knoweledge, this is first report of combined use of advanced surface analytical techniques (e.g. VSI) and rate spectral analyses to examine the effects of aqueous solution concentration on dolomite surface rate heterogeneity and quantification of rate contributors. These results have implications for a variety of aqueous environments, where carbonate mineral stability is governed by the aqueous solution concentration and $\mathrm{pH}$. 